Prof. Nichols electroplates a strip I millimetre wide of the carbon rod parallel to the axis with copper to the required thickness. The influence of temperature up to $100^{\circ} \mathrm{C}$. is then entirely imperceptible.

Messrs. Glazebrook and Fitzpatrick have once more utilized the resources of the Cavendish Laboratory to determine the specific resistance of mercury, and therefore the value of the ohm (IO C.G.S, units of resistance). The result, together with the most recent determinations, is given in the following table :-

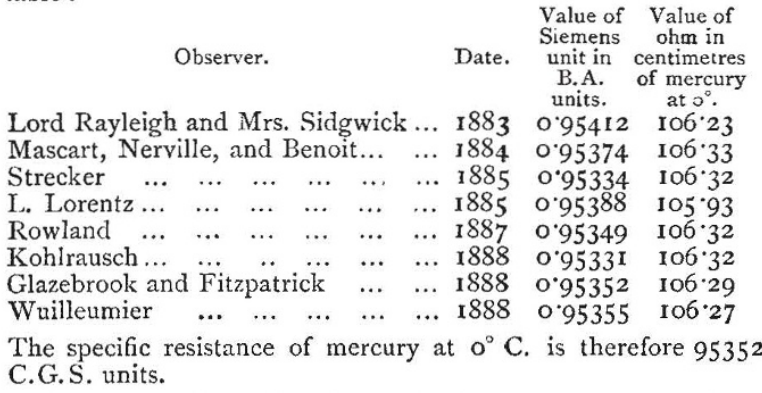

THE mean of the values in centimetres of mercury-106.3 omitting Lorentz's, must be considered a very close approximation to the true ohm. We thus have

$$
\begin{array}{lllll}
\text { B.A. unit } \ldots & \ldots & \ldots & \ldots & \text { 104.808 cm. } \\
\text { Legal ohm } & \ldots & \ldots & \ldots & \text { 106 } \\
\text { Ohm } \ldots & \ldots & \ldots & \ldots & \text { 106.3 }
\end{array}
$$

The B.A. unit is thus 1.347 per cent. wrong.

WHAT is the specific resistance of pure copper? is a curious question to ask in 1888 , but Mr. G. P. Prescott asks it in the Electrical Engineer of New York. He points out that Ayrton gives it as I.599, and Stewart and Gee $1 \cdot 616$, legal microhms, at the same ternperature, $0^{\circ} \mathrm{C}$. $\mathrm{He}$ also shows that Matthiessen and Jenkin did not agree; they differed 2.3 per cent. Messrs. Glazebrook and Fitzpatrick, who have done such good work with mercury, might well turn their attention to copper. It is well known that Matthiessen's standard for pure copper is wrong. It was one English standard mile of pure annealed copper wire $\mathrm{I} / \mathrm{I} 6 \mathrm{inch}$ in diameter at $15^{\circ} \cdot 5 \mathrm{C}$., having a resistance equal to $13.59 \mathrm{~B}$.A. units. It is a common thing to get copper giving better results than this.

THE magnetic elements for 1887 as determined at Greenwich were-

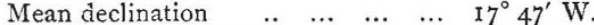

$$
\begin{aligned}
& \begin{array}{lllll}
\text { Mean horizontal force } & \ldots & \ldots & \ldots & 181^{\circ} 75
\end{array}
\end{aligned}
$$

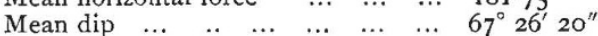

Why does the Astronomer-Royal retain British and metric units when nearly all the world uses C.G.S. units?

\section{THE MICRO-ORGANISMS OF AIR AND WATER.}

F VER since the great importance of micro-organisms in the economy of Nature was pointed out by Pasteur now some twenty-five years ago, the presence of these minute living forms in the two great fluid media - air and water-with which we are surrounded, has formed the subject of elaborate investigations. As these investigations are thus co-extensive with the period during which micro-organisms have been made the subject of careful study, a review of them becomes particularly instructive as illustrating the gradual development of the methods of bacteriology from the earliest times up to the high degree of perfection to which they have attained at the present day.

It was Pasteur himself who first instituted a systematic inquiry into the presence and distribution of micro-organisms in the atmosphere in connection with his well-known researches disproving the spontaneous generation of life. The experiments which he undertook for this purpose are as remarkable for their extreme simplicity as for the striking results which they yielded. Thus the apparatus with which Pasteur set about exploring the distribution of microbes in the air consisted simply of a number of small flasks, each partially filled with a putrescible liquid such as broth; the necks of these flasks were drawn out and sealed before the blow-pipe whilst the fluid contents were in active ebullition. The flasks thus prepared were both vacuous and sterile, and could be preserved for an indefinite Iength of time without the contained liquid undergoing change. A number of these flasks were then momentarily opened in various places-in Paris, in the open country, at various altitudes in the Jura Mountains, and at an elevation of 6000 feet at the Montanvert, near Chamonix. Each flask on being opened became instantly filled with the air of the place in question, whilst, by sealing the flask directly afterwards, the further access of air was prevented. On preserving these flasks which had been thus opened, the liquid of some was found to become turbid and lose its transparency owing to the development of bacterial life within it, whilst in others it remained perfectly clear and translucent. It was further observed that the proportion of flasks becoming so affected varied greatly according to the places where they had been exposed. Thus, of twenty flasks exposed in the open country near Arbois, eight developed living organisms ; of twenty opened on the lower heights of the Jura Mountains, five became affected; whilst of the twenty opened at the Montanvert, close to the Mer de Glace, only one broke down. The proportion of flasks which became affected on being similarly exposed in Paris, was considerably greater than in the case of the experiment made at Arbois.

The results of these simple experiments thus convey a most vivid picture of the great density of microbial life in the air of towns, and of its attenuation in the higher regions of the atmosphere, although they can give no account of the actual numbers present in the air under examination.

Miquel and Freudenreich ${ }^{1}$ made the first step in the quantitative estimation of aërial microbes by aspirating air through plugs of glass-wool, thus taking advantage of a fact long known -that it is impossible for micro-organisms to pass through sufficiently tightly constructed plugs of such materials.

Without entering into a detailed account of this method, the merits and demerits of which have been fully discussed by German investigators, it is sufficient to state that a very large number of experiments have been carried out by the authors which can lay clain to a fair degree of accuracy. However, since solid nourishing media for the cultivation of microorganisms were introduced by Koch, the importance of substituting the latter for the liquid media hitherto exclusively employed has led experimenters to devise processes which shall render their use possible in the examination of air.

The advantages possessed by solid over fluid media are very great, for whereas in fluid media, such as broth, the organisms are in no way restricted in their movements, and their multiplication can take place indiscriminately throughout the entire liquid, on the other hand, if they are introduced into gelatinepeptone which has been first melted, they can be evenly dispersed throughout the culture-material by gentle agitation, and by subsequently allowing it to solidify they are not only isolated, but rigidly confined to one spot. Thus each individual organism becomes a centre round which extensive multiplication takes place, and in a few days definite points of growth are visible to the naked eye, which are appropriately described as "colonies," and which can be easily counted with the aid of a low magnifying glass. Although each colony consists of many thousands or even millions of individual microbes, yet as in the first instance they owe their origin to a single organism or indivisible group of organisms, it is correct to regard the number of colonies as representing the number of micro-organisms. These colonies have often very beautiful and characteristic appearances, ${ }^{2}$ and it is exceedingly remarkable how constant and distinct for one and the same organism these appearances are. In many cases they give rise to magnificent patches of colour-deep orange, chrome yellow, brown, various shades of red, green, black, \&c. Often under a low magnifying power they are seen to spread over the surface of the gelatine, producing tangled networks of threads, sometimes they resemble the petals of a flower, sometimes the roots of a tree or its branches; in fact, one is constantly startled by the novelty and beauty of their modes of growth.

Koch ${ }^{3}$ and, later, Hesse ${ }^{4}$ have devised methods by which the organisms in the air become deposited on a solid surface of gelatine-peptone, and by there producing colonies render their estimation possible. A large number of experiments have been

I "Annuaire de l'Observatoire de Montsouris," I879-86. "Studies on some New Micro-organisms obtained from Air," Phil. Trans., vol. clxxviii. p. 257.

3 Mittheilungen aus dem kaiserlichen Gesundheitsante, $188 \mathrm{x}$, Bd. i.

4 Ibid., $x 883$, Bd. ii. 
made with Hesse's method, which consists in aspirating air through glass tubes about 3 feet in length, coated internally with a film of gelatine-peptone. The organisms, owing to the property they possess of rapidly subsiding in the absence of disturbing influences, fall on the surface of the gelatine, and give rise to colonies.

The following series of observations was made by this method in $1886^{1}$ on the roof of the Science Schools, South Kensington Museum, in order to trace the seasonal variations in the number of micro-organisms present in the air of one and the same place. The following are the averages obtained for each month during which these observations were made :-

Number of Micro-organisms found in Ten Litres (Two Gallons) of Air.

\begin{tabular}{|c|c|c|c|c|c|c|c|}
\hline January & & & & 4 & August $\ldots$ & & \\
\hline March & ... & $\ldots$ & $\ldots$ & 26 & September & $\ldots$ & ... \\
\hline May & ... & ... & ... & $3 \mathrm{I}$ & October ... & $\ldots$ & $\ldots$ \\
\hline June & $\ldots$ & ... & $\cdots$ & 54 & November & $\cdots$ & $\cdots$ \\
\hline Tuly & ... & $\ldots$ & $\ldots$ & 63 & December & $\ldots$ & $\ldots$ \\
\hline
\end{tabular}

From these figures it will be seen that it is during the summer that the largest number of micro-organisms are fuund in the air, whilst the smallest average number was recorded in the month of January.

The air at sea, the air at higher altitudes, and the air in sewers, have all been explored by means of Hesse's method.

Thus Dr. Fischer, ${ }^{2}$ in experiments carried on at sea, found that beyond a distance of 120 sea miles from land microorganisms were invariably absent. And, inasmuch as microorganisms are abundantly present in sea-water, it thus appears that no micro-organisms are communicated to the air from the water even when the latter is much disturbed. Moreover, as might have been anticipated, this complete freedom from microorganisms was attained even in close proximity to land, provided the wind had passed over the above-mentioned distance of sea.

As regards the air at higher altitudes, experiments have been made on the dome of St. Paul's, in London, and on the spire of Norwich Cathedral, which show that even in ascending to such modest elevations in densely-populated centres, the number of micro-organisms suspended in the air undergoes very marked diminution.

Thus, on the top of Norwich Cathedral spire, at a height of about 300 feet, I found in ten litres (two gallons) of air only seven micro-organisms, and on the tower, about I8o feet high, I found nine, whilst at the base of the Cathedral, in the Close, eighteen were found. These results are fully confirmed by another series of experiments made at St. Paul's Cathedral. In this case the air examined from the Golden Gallery yielded in the same volume eleven, that from the Stone Gallery thirty-four, whilst in the churchyard there were seventy micro-organisms present.

The contrast between town and country air, and even between the air of the London parks and streets is also exceedingly sharp. In Hyde Park - the place selected for the experiment being as far removed from roads and traffic as possible-I found eighteen, whilst on the same day, June 7 , the air in the Exhibition Road, South Kensington, yielded as many as ninetyfour. On the following day, however, when the traffic was very great, and the air was consequently heavily laden with dust, the number rose to 554 . This is in marked contrast to the microbial condition of country air, for on the Surrey Downs in the same volume only two micro-organisms were found; and in the case of an extensive heath near Norwich only seven.

Within doors we find that the number of micro-organisms suspended in the air depends, as we should have expected, upon the number of people present, and the amount of disturbance of the air which is taking place. Thus, on examining the air in the large entrance hall of the Natural History Museum in Cromwell Road it was found to yield under ordinary condition from fifty to seventy organisms in the same volume (two gallons), but on Whit Monday, when an immense number of visitors were present in the building, I found as many as 28o. Again, on a paying day at the South Kensington Museum, about eighteen micro-organisms were found, but on the Saturday, when no en-

I “"The Distribution of Micro-organisms in Air," Proc. Roy. Soc., No. 245, 1885: "Further Experiments on the Distribution of Micro.organisms in Air," Proc. Roy. Soc., vol. xlii. p. 267 , 1886.

"Bacteriologische Untersuchungen auf einer Reise nach Westindien," Zeitschrift fiir Hysiene, Bd. i. Heft 3 . trance fee is charged, there were as many as seventy-three in the same volume of air.

The air of sewers has been shown by Carnelley in this country, and by Petri in Berlin, to be remarkably free from microorganisms, the number being almost invariably less than in outside air. That this should be the case is only natural when the moist nature of the walls and the absence of dust in these subterranean channels is borne in mind, and although their liquid contents is teeming with bacterial life, there is no reason why the latter should be carried into the air provided no effervescence or splashing takes place. On the other hand, if the contents of a sewer enter into fermentation and bubbles of gas become disengaged, minute particles of liquid with the living matter present may be carried to great distances, and it must not, therefore, be too hastily concluded that because sewer air is generally remarkably free from micro-organisms, that, therefore, a visit to the sewers should be attended with such beneficial results as a trip to sea or the ascent of a mountain summit !

During the use of Hesse's method I became acquainted with several serious defects which it possessed, and in order to overcome these disadvantages I was led to devise a new process ${ }^{1}$ for the examination of air. This consists essentially in aspirating a given v.lume of air through a small glass tube, not more than 4 inches long and $\frac{1}{4}$ inch in width, which is provided with two filter-plugs, the first of which is more pervious than the second, and consists of glass-wool coated with sugar, whilst the second contains, in addition, a layer, $\frac{1}{3}$ inch in thickness, of fine sugarpowder. On these plugs the microbes suspended in the aspirated air are deposited, and each of these plugs is then introduced into a separate flask containing a small quantity of melted gelatine-peptone; with this the plug is agitated until it becomes completely disintegrated, and since the sugar-coating of the glasswool dissolves in the liquid gelatine, the microbes become immediately detached. The contents of the flask are then made to congeal in the form of a thin film over its inner surface. The flasks are then preserved at a suitable temperature, and in the course of a few days the colonies derived from the organisms, which were collected by the plug, make their appearance and can be counted and further studied. Now, if the plug has been properly constructed, the flask into which the second or more impervious plug has been introduced will be found to remain quite sterile, clearly showing that the first plug has arrested all the microbes suspended in the aspirated air. This method yield results which agree not only very closely amongst themselves, but also with those obtained by Hesse's method, if the experiments are made in still air, which is the condition necessary for an accurate result being obtained with a Hesse tube. As this new method is equally applicable in disturbed air, it possesses great advantages over Hesse's, and is, moreover, considerably more convenient, as it renders possible the examination of a far larger volume of air in a very much shorter space of time, the apparatus required being also exceedingly portable.

Of the presence of pathogenic or disease-producing microorganisms in air, there is little or no direct evidence so far; it must, however, be remembered that it is just in the case of those extremely infectious diseases, such as measles, whooping-cough, \&c., in which the virus might be expected to be carried through the air, that the exciting organized poisons have not yet been discovered and identified.

The investigations on aërial microbia, so far as they have as yet been carried, are of service in indicating how we may escape from all micro-organisms, whether harmful or harmless; and secondly, how we may avoid the conveyance of micro-organisms into the atmosphere from places where pathogenic forms are known or likely to be present. This acquaintance with the distribution of micro-organisms in general, and the power of controlling their dissemination which it confers, is really of far wider practical importance than discovering whether some particular pathogenic form is present in some particular sample of air. It is this knowledge which has led to the vast improvements in the construction and arrangement of hospital wards and of sick-rooms generally, and which has directed attention to the importance of avoiding all circumstances tending to disturb and distribute dust. It is, moreover, this knowledge of the distribution of micro-organisms in our surroundings which has formed one of the foundations for the antiseptic treatment of wounds- that great step in surgery with which the name of Sir Joseph Lister is associated.

I “A New Method for the Quantitative Estimation of the Micro-organisms present in the Atmosphere," Phil. Irans., vol. clxxviii. p. II3. 


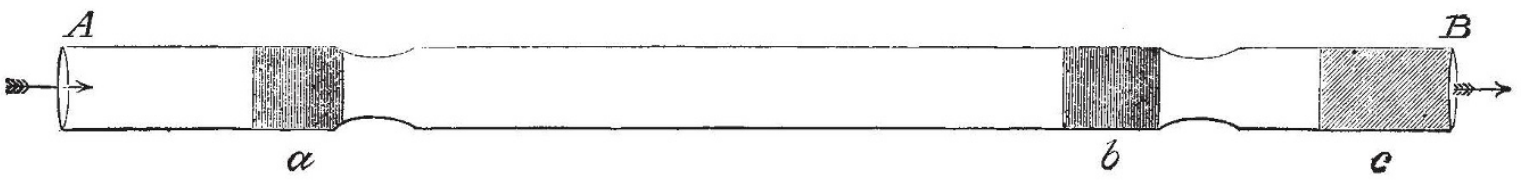

FIG. I.-Glass tube througt which the air is aspirated: about the original size. A, aperture of tube through which the aspirated air enters; B, exit of aspirated air; $a$, first filter-plug, consisting of glass-wsol; $b$, second filter-plug, consisting of glass-wool and powdered glass or sugar ; $c$, cottonwool plug to protect plug $b$.

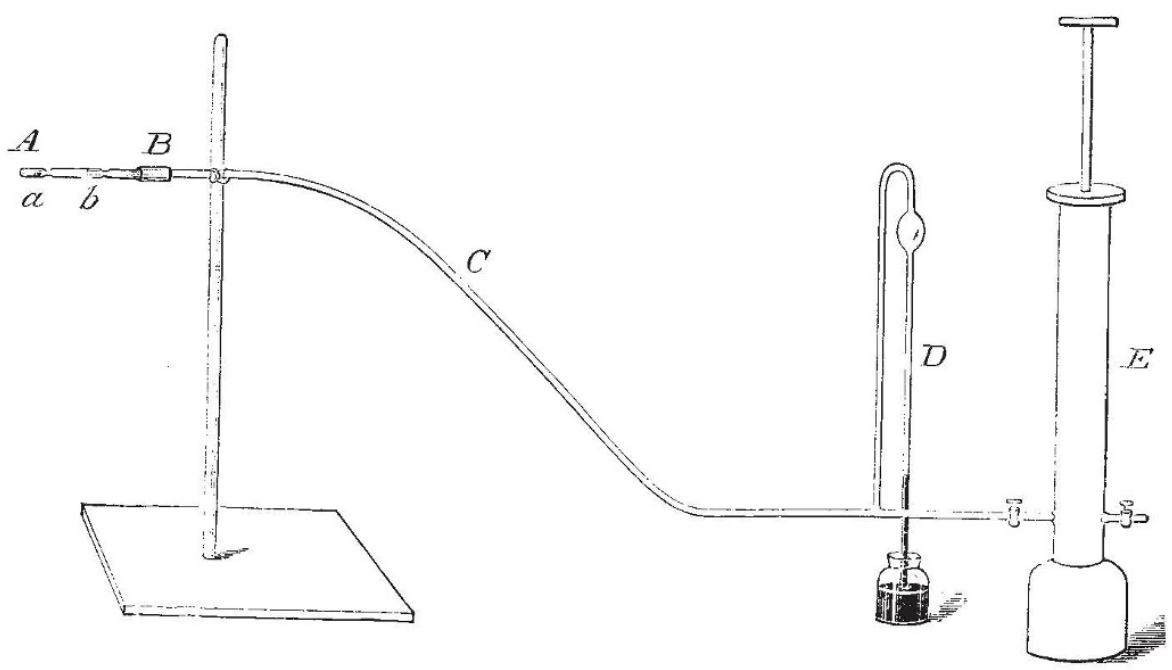

FIG. 2.-Arrangement of the apparatus for taking a sample of air. A, B, the filter tube; C, lead tubing, about xo feet in length; D, mercury pressuregauge; $E$, air-pump.

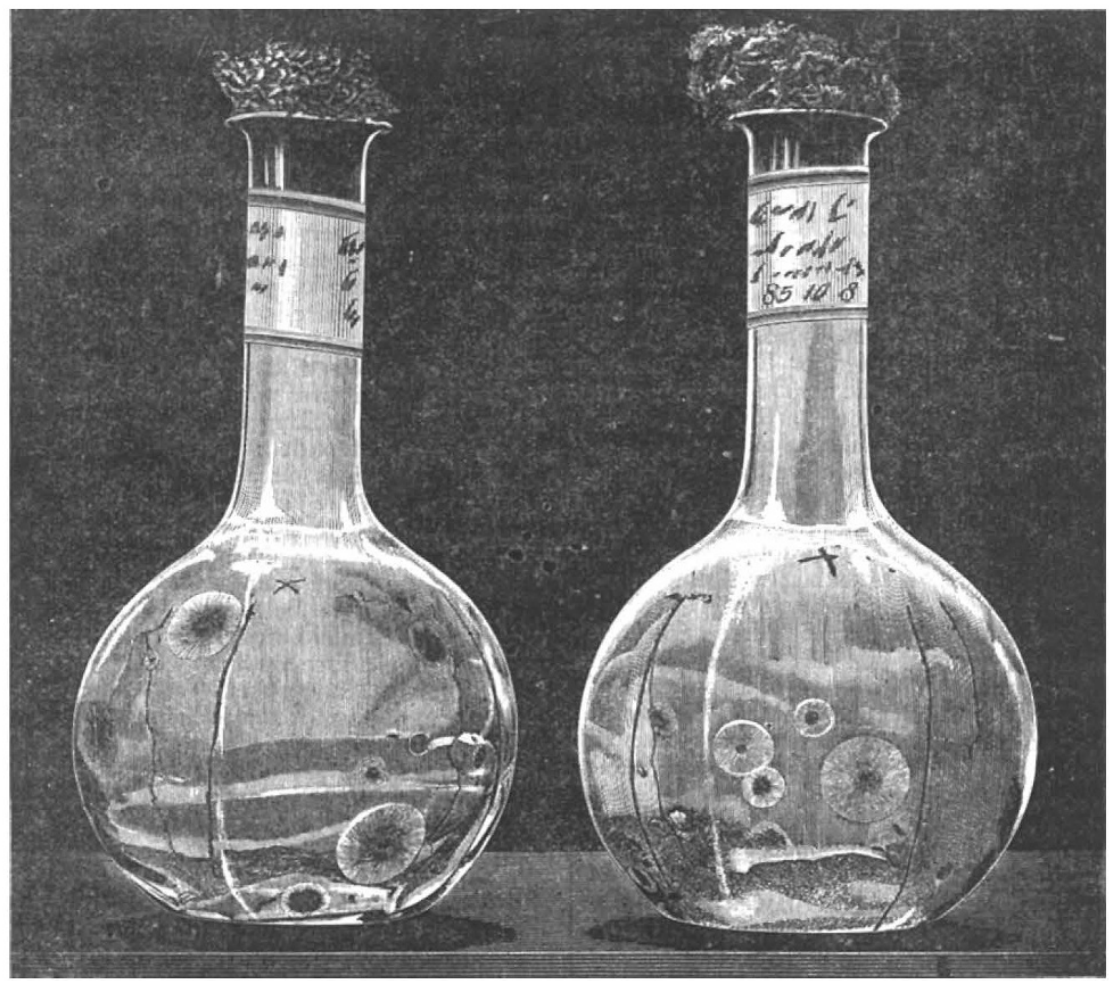

rig. 3.-Flasks after incubation, showing colonies on film of gelatine with which the inner surface is coated. 


\section{Micro-organisms in Water.}

The micro-organisms present in water have long been studied by direct observation with the microscope. Such observations can, however, only be made in the case of foul waters in which bacterial life is very abundant, and even in such cases the information gained by the microscope alone has but little value. It is to the modern methods of cultivation, more especially those in which solid media are employed, that our increased knowledge concerning these primitive inhabitants of water is due. Thus the beautiful process of plate-cultivation introduced by Koch, ${ }^{1}$ and to which more than to anything else the recent advances in bacteriology are due, has been of the greatest service in the investigation of a number of questions bearing on the microorganisms in water. The method of plate-cultivation consists, as is well known, in taking some of the liquid or other substance under examination for micro-organisms and mixing it with melted gelatine-peptone in a test-tube, the mixture being then poured out on a horizontal plate of glass and allowed to congeal, the plate being then preserved in a damp chamber at a suitable temperature. In the course of a few days colonies make their appearance in the gelatine film, and can be counted and further studied as required. This process is of extremely wide application, for by this means pure cultivations of the various organis ns in a mixture can be readily obtained. If a definite volume of water be submitted to this method of plate-cultivation, the resulting colonies on the plate clearly indicate both the number and the character of the organisms present in it.

From numerous investigations made by means of gelatine plate-cultivations, it appears that whilst surface waters, such as rivers, contain an abundance of microbial life, waters, which like those from springs and deep wells have undergone filtration through porous strata, contain but very few microorganisms. Now since such underground waters have at some time or other been surface waters, it is obvious that in passing through the porous strata of the earth they have been deprived of those microbes which they contained whilst at the surface. This removal of micro-organisms from water ${ }^{2}$ also takes place in a very marked manner when it is submitted to some kinds of artificial filtration, such as that through very finely divided colie or charcoal, as well as in the filtration of water on the large scale through sand. The process of filtration, however, which absolutely removes microbes with the greatest degree of certainty is that introduced by Pasteur, in which the water is forced through porous porcelain. It is especially noticeable that the efficiency exhibited by these various materials in removing micro-organisms stands in no sort of relationship to their chemical activity, i.e. power of removing organic matter from water. Thus the porous porcelain produces practically no change whatever in the chemical composition of the water, whilst it deprives it entirely of micro-organisms.

The relative abundance of bacterial life in surface water, in deep well water, as well as in surface water after filtration through sand on the large scale, is well illustrated by the following results.

Thus the average number of micro-organisms obtained during the past year from a cubic centimetre (about twenty drops) of the raw water as abstracted from the Rivers Thames and Lea by the metropolitan water companies was 21,500 and 13,200 re spectively. The same water, however, after having undergone storage and filtration contained on an average respectively 500 and 450 micro-organisms in I cub:c centimetre. It is at once apparent, therefore, what striking results can be obtained by sand filtration as at present carried out, and there is no doubt that with the introduction of fresh improvements and increased care an even greater reduction will be effected.

In deep well water obtained from the chalk, which has undergone no artificial filtration, we find the remarkably low nu nber of eighteen as the average for the year. Thus the artificial filtration through sand is far surpassed by the exhaustive filtration through vast thicknesses of porous strata.

Another point which has been brought to light thr ugh investigating the micro-organisms of water by means of the improved methods which we now possess is that many of the microbes found in natural waters are capable of the most abundant multiplication ${ }^{3}$ in the absence of practically any orgaric matter

I Mittheilungen aus dem kaiserlichen Gesundheitsante, Bd. i., r88r. No. 238,1885 .

No. "On the Multiplication of Micro-organisms," Proc. Roy. Soc., No. 245, 1886. "Ueber das Verhalten versc'lied. Bacterienarten im Trinkwasser," Meade Bolton, Zeitschrift fïr Hygiene, Bd. i. Heft I. whatever. Thus, if the deep well water referred to above is preserved for several days thoroughly protected from contamination through the air, and is then examined for micro-organisms, it will be found that these have undergone an enormous increase, I cubic centimetre containing many thousands instead of the ten or twenty usually present in the water at the time of pumping. It has been found, moreover, that some of the water-organisms are even capable of such abundant multiplication in water which has been several times redistilled, and which is, therefore, almost absolutely pure. From what source such organisms obtain their necessary nourishment under these circumstances has not yet been determined. The following figures serve to illustrate the extent to which multiplication of this kind may take place :-

\section{Number of Micro-organisms obtained from I cubic centimetre} of water.

Day of Collection. Standing $\mathbf{r}$ day
at $20^{\circ} \mathrm{C}$. $\begin{gathered}\text { Standing } 3 \text { days } \\ \text { at } 20^{\circ} \mathrm{C} \text {. }\end{gathered}$ $\begin{array}{lllllll}\text { Kent Co.'s deep well } & 7 & \ldots & 2 \mathrm{I} & \ldots & 495,000\end{array}$

It is often urged that the bacteriological examination of water is of little practical importance, inasmuch as the micro-organisms found are not necessarily prejudicial to health, and that the method of examination does not aim at the detection of harmful forms. A little more mature consideration, however, will show that the actual detection of harmful or pathogenic forms is a matter of very little importance, and that if methods of water purification are successful in removing micro-organisms in general, and more especially those which find a suitable home in natural waters, there can be no serious doubt that they will be equally successful in removing hamful forms, which are not specially adapted for life in water. Could it be, fur instance, reasonably contested that a method of purification which is capable of removing the Bacillus aquatilis from water, would be incapable of disposing of the Bacillus anthracis when suspended in the same medium? The supposition is, on the face of it, absurd, and not a particle of experimental evidence can be adduced in its favour. It is, therefore only rational to conclude that those methods of water purification, both natural and artificial, which succeed in most reducing the total number of micro-organisms, will also succeed in most reducing the number of harmful forms should they be present.

As a matter of fact, however, pathogenic forms can and have been discovered in waters by the process of plate-cultivation; thus the "comma-bacillus," which is by many authorities regarded as the cause of Asiatic cholera, was found by Koch in some tank-water in India, and the bacillus which with more or less probability is identified with typhoid fever has by Chantemesse and Widal been discovered in the drinking-water which had been consumed by persons suffering from that disease.

On the other hand, the examination of water for the number of micro-organisms present can have no value if the multiplication referred to above has taken place. Thus, if the number of micro-organisms present in a water is to throw light on the natural purification it has undergone, the sample for examination must be taken as near as possible to the point where it issues from the water-bearing stratum, and, in the case of artificially purified water, as soon as possible after it has left the purifying apparatus.

Of much more importance than the discovery of pathogenic organisms in particular waters is the problem of ascertaining the fate of pathogenic forms, when these are introduced into waters of different kinds. A considerable amount of work has been done in this direction with a number of typical pathogenic forms, ${ }^{1}$ and some very remarkable results have been obtained. Thus it has been found that the bacilli of authrax do not survive many hours on being introduced into ordinary drinking-water; their spores, however, are not in any way affected by such immersion, and even in distilled water the latter retain their vitality for practically an indefinite length of time. In polluted water, such as sewage, on the other hand, not only do the bacilli not succumb, but they undergo extensive multiplication. Similarly Koch's "comma-bacillus" was found to flourish in sewage, being still present in very large numbers after eleven months residence in this medium. In deep-well and filtered Thames water, on the other hand, although the "cumma-bacilli" were

I “Die Vermehrung der Bacterien im Wasser" Wolffhügel und Riedel, Arbeiten a. d. kaiserlichen Gesundheitsamte. "Ueber das Verhalten, \&c.". Meade Bolton. "On the Multiplication of Micto-organisms," Proc. Roy. Soc.; also " Recent Bacteriological Research in connection with Water Supply," Soc. Chem. In 1., vul. vi. No. 5. 
still demonstrable after nine days, they were only present in small numbers. Much less vitality is exhibited by the micrococcus of erysipelas when introduced into waters of various kinds, for even in sewage this organism was not demonstrable on the fifth day. In fact, all the pathogenic micrococci which have been experimented with in this"manner exhibit but little vitality under similar circumstances.

From these experiments it appears, therefore, that whilst ordinary drinking-water does not form a suitable medium for the extensive growth and multiplication of those pathogenic forms which have hitherto been made the subject of investigation in this respect, yet, that in the condition of spores, they are extremely permanent in any lind of water, however pure, and that even those of which no spores are known may often be preserved for days or even weeks.

Thus the investigations which have hitherto been made on the micro-organisms both of air and water, by the light which they throw on the behaviour of micro organisms in general in these media, the manner in which they may be preserved and the manner in which they may be removed, are of great service in indicating how the spread of zymotic diseases through these media is to be avoided.

Until we are fully acquainted with all pathogenic forms of microbes, a consummation which is certainly not likely to be attained in the near future, it is obvious that in endeavouring to exclude dangerous organisms we must attempt to exclude all organisms, e.g. in the purification of water which has been exposed to possibly noxious pollution, that process of purification which insures the removal or destruction of the greatest proportion of micro-organisms must be regarded as the most efficient. In just the same way as in the antiseptic treatment of wounds, the preventive measures employed by surgeons are of such a nature as to destroy or preclude the possibility of growth of any microbes whatever, and not only of those known to be capable of causing mischief.

Percy F, Frankland.

\section{THE OPENING OF THE MARINE BIOLOGICAL LABORATORY AT PLYMOUTH.}

THE Laboratory erected at Plymouth by the Marine Biological Association of the United Kingdom, of which a full account was given last week in NATURE, was opened on Saturday, June 30 . The weather was fine, and at ten o'clock a large and distinguished company were present. Having viewed the tanks, the company assembled in the Laboratory, where Prof. W. H. Flower, C.B., F.R.S., Director of the Natural History Department of the British Museum, delivered an address, in the course of which he said :- "The necessity for such institutions as this has been felt almost simultaneously throughout the cultivated nations of the world. The British Isles, with their extensive and varied seaboard, offering marvellous facilities for the investigation of marine life, with their vast economical interests in the denizens of the waters that lave their shores, have been rather behind some other countries in adopting this line of research. Let us hope, however, that being so, we may profit by example and the experience of others, and ultimately, as in so many other similar cases, may outstrip our neighbours in a department of work for which our maritime and insular position seems so specially to fit us. That our country should be alone in neglecting this branch of scientific inquiry was impossible. Stations for the investigation of the phenomena of marine life have been founded at several places on the northern coasts of our island, but all on a very limited scale. An institution commensurate with the importance of the subject and of the nation had to be established sooner or later; the only questions to be solved were when it was to be founded and where it was to be placed. Much of the success of an enterprise must depend upon the particular time selected for embarking upon it. If delayed too long, the world is a loser by the non-existence of the knowledge that is to be gained from it. On the other hand, premature attempts before sufficient interest in the subject is awakened, or before sufficient information as to the best means of carrying it out has been gained, often end in failure. I think that in this respect we have taken the right medium." After a reference to the Fisheries Exhibition, Prof. Flower continued: - "The question as to the place at which our head-quarters were to be established was at first one of considerable difficulty. Many were the rival claimants, but Plymouth was finally chosen as best approaching the requisite physical and geographical surroundings for such an institution; and the cordiality with which the Association was welcomed by its leading citizens was in itself a ground of justification for the choice. Though a portion of the old military defences of the town has been given tip to our peaceful enterprise, we trust the safety of the inhabitants will not suffer. The Laboratory now stands beneath the Plymouth Citadel and the sea, and an enemy entering the town by the most direct route would have to march over the ruins of the building. That consideration alone should be enough to secure your safety in a war with many of the enlightened science-loving nations of Europe, should such an event unhappily arise. As to the institution itself, few words are needed to show how excellent is its adaptation to the purpose for which it is founded. Although still not in all respects. in full working order, we have been all enabled to see to-day how carefully it has been planned, and how well the design has been carried out. We have secured a capable and energetic working staff, students are already taking their places at our laboratory tables, and already a commencement has been made in their original investigations and contributions to knowledge, which we hope will be of such a character and of such abundance as to give this Laboratory a high place among the scientific institutions of the world. Our present financial position and our future needs are fully set forth in the report of the Council, just issued. This shows that of our capital already subscribed the greater part has been expended on the building and the necessary apparatus for its equipment. We still want a steam-vessel for the use of the staff in exploring the fishing grounds of the neighbourbood and for collecting materials to stock our tanks; and for the means of providing this, and for the annual maintenance of our establishment in a state of efficiency, we shall require further pecuniary assistance. But as the rep ort is, or shortly will be in your hands, I need not detain you longer by enlarging upon its contents. I will therefore, in the name of the President and Council of the Marine Biological Association of the United Kingdom, thank all those who have, by their generous contribution of money or by expenditure of their time, labour, and thought, brought us so far on our way, and declare the Laboratory of the Association open for work. May we all join in the earnest hope that the expectations which have been raised of its future usefulness may never be disappointed."

The company, after being photographed, adjourned to the Grand Hotel on the Hoe, where they sat down to a díjeitiner given by the Fishmongers' Company. Sir James Lawrence, Prime Warden of the Fishmongers' Company, presided, and was supported by the Earl of Morley, Prof. Flower, Sir H. W. Acland, K.C.B., F.R.S, the Mayor of Plymouth (Mr. H. J. Waring), the Mayor of Devonport (Mr. J. W. W. Ryder), the Chairman of the Stonehouse Local Board (Mr. E. A. Lyons), Prof. E. Ray Lankester, LL.D., F.R.S., Sir Edwin Saunders, Sir George Paget, K.C.B., F.R.S., the Ven. Archdeacon Wilkinson, Prof. A. Milnes Marshall, F.R.S., Prof. Charles Stewart, Mr. J. Evans, P.S.A., F.R.S., Captain Wharton, R.N., F.R.S., the Vice-Chancellor of Cambridge, Sir Edward Watkin, M.P., Prof. J. W. Groves, Rear-Admiral H. D. Grant, C.B., MajorGeneral T. C. Lyons, C.B., Mr. Thiselton Dyer, C.M.G., F.R.S., Mr. A. Sedgwick, F.R.S., Mr. W. Pengelly, F.R.S. Mr. F. Crisp, F.R.S., Colonel Hewet, R.E., Rev. J. Hall Parlby, Dr. A. Giinther, F.R.S., Major-General Barton, R.E. Captain Inskep, R. M., Mr. Robert Bayly, Prof. F. Jeffery Bell, Prof. D'Arcy 'Thompson, Prof. G. B. Howes, Mr. C. Spence Bate, F.R.S., Prof. M. Foster, Mr. W. Lant Carpenter, Mr. E. W. N. Holdsworth, Mr. E. L. Beckwith, Fishmongers' Company, Mr. Gilbert C. Bourne, and Mr. J. Solly Foster and Mr. John Hall, Wardens, Fishmongers' Company.

The health of "The Queen" having been given by the Chairman, Lord Morley proposed "The Marine Biological Association of the United Kingdom." He said he was sure that his friends the Mayors of Plymouth and Devonport would join with him in wishing a hearty welcome to the Association, and in sincerely hoping that the Laboratory would prove a success. Any doubt as to the practical value of the Laboratory was dissipated by the fact that the Chairman was one of its main founders, and also that many well-known gentlemen, including the Chairman of the National Association at Kensington and Kew, anticipated good results therefrom. Since there was such a consensus of opinion as to the importance of the scheme from a practical and scientific point of view, the thing which surprised him was why. it was not done before. We reaped the richest harvest from the sea, and yet we had never inquired scientifically into the source 